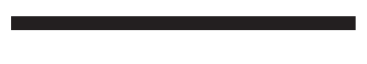

AUTORES:

F. M. Santos ${ }^{1}$

M. O. Barbosa ${ }^{1}$

P. C. A. Montenegro

Universidade Federal de Alagoas, Maceió, Alagoas, Brasil

\section{A motivação e aprendizagem dos alunos diante das tecnologias de informação e comunicação nas aulas do PIBID de Educação Física}

\section{PALAVRAS CHAVE:}

Tecnologia de informação e comunicação,

Educação Física. Programa institucional

com bolsa de iniciação a docência. Motivação.

\title{
RESUMO
}

Estudo da motivação e facilitação da aprendizagem quando há utilização das mídias e tecnologia. A população pesquisada foi formada pelos estudantes do ensino médio das turmas participantes do Programa Institucional com Bolsa de Iniciação a Docência de Educação Física, em uma escola da rede pública. Os resultados demonstram que $50 \%$ dos alunos investigados se consideram mais motivados com as estratégias de ensino que se utilizam das Tecnologias de Informação e Comunicação nas aulas. 97\% dos alunos relataram que esses recursos são mais atrativos, melhorando a concentração e atenção. Desta feita, foi possível analisar como benéfico esse processo de ensino-aprendizagem, entretanto, nem sempre a escola é capaz de fornecer o suporte para que isto aconteça de forma mais producente.

The motivation and learning of students

in relation to the information and

communication technologies in PIBID's

Physical Education classes

\section{ABSTRACT}

Study of motivation and facilitation of learning when there is use of media and technology. The population studied was formed by high school students of classes participating in the Institutional Program with Initiation Scholarship of Teaching in Physical Education, in a public school. The results show that $50 \%$ of students surveyed consider themselves more motivated to participate of strategies that use of Information Technologies and Communication in the classroom. 97\% of students reported that these features are more attractive, improving concentration and attention. This time, it was possible to analyze how beneficial was this process of teaching and learning, however, the school is not able to always provide the support to make this happen more productive way.

KEY WORDS:

Information and communication technology. Physical Education.

Institutional initiation scholarship with the teaching.

Motivation program. 


\section{INTRODUÇÃo}

Atualmente é perceptível que a tecnologia, as mídias e os meios de comunicação estão cada vez mais presentes em nosso cotidiano nos auxiliando de diversas formas. Neste contexto quem mais se adaptou as novidades recorrentes foram os jovens, pelo maior uso destas tecnologias. No entanto, ainda é um desafio para muitos educadores o seu uso pela pouca informação sobre a utilização desses meios como recursos de ensino. 0 desafio da educação é preparar os educadores em serviço para desfrutar destas tecnologias no planejamento de suas atividades didáticas. Aos poucos, as novidades tecnológicas entram no cotidiano das escolas trazidas pelos próprios alunos. Segundo Lima ${ }^{(1)}$ os professores precisam repensar suas práticas e entender como os jovens de hoje aprendem mais e melhor.

Em qualquer escola que visitarmos hoje é fácil encontrar com os alunos equipamentos eletrônicos como: celulares, $\mathrm{mp} 3, \mathrm{mp} 4$, tablets, dentre tantos outros recursos tecnológicos. Algo que para os jovens chamam mais a atenção do que o ambiente da sala de aula e que o professor normalmente não sabe ou não esta preparado para lidar com isso. De acordo com Amadeu ${ }^{(2)}$ a simples repressão é ineficaz, sendo necessário investir em políticas de inclusão digital, onde a conscientização dos alunos só deve surgir através da utilização do dialogo entre os sujeitos envolvidos, sendo estes: educadores, pais e alunos.

Então o que seriam as Tecnologias da informação e comunicação? Marquès ${ }^{(3)}$ aponta que estas fazem parte do conjunto de avanços tecnológicos que transmitem dados/informação/conhecimento e estes são apresentados através de tecnologias audiovisuais que se relacionam através da informática, telecomunicações, a internet, mídias de massa, aplicações multimídia e a realidade virtual.

Sebriam (4) cita ainda que se devam tratar as transformações que vem ocorrendo no âmbito escolar de forma criteriosa para que não ocorra por modismo e que o uso das TIC deve ser sempre buscado para melhorar a educação que a escola oferece.

Sendo uma disciplina como as demais a Educação Física vem se resignificando através dos anos e mudando seus objetivos e metodologias empregadas, par e passo com (in clusive para tentar acompanhar) o desenvolvimento tecnológico que ocorre também no ambiente escolar, esta é visualizada como uma disciplina voltada para a cultura corporal do movimento. E isto também foi foco do subprojeto de Educação Física do Programa Institucional de Bolsa de Iniciação à Docência - PIBID, que teve como objeto de estudo o corpo humano em movimento e suas transformações que utilizou das TIC para facilitar a aprendizagem dos conteúdos previstos na disciplina pelos alunos das turmas envolvidas no programa. Assim esse programa visou melhorar as condições de ensino oferecidas nas aulas de Educação Física, na escola X, visando o maior desempenho dos escolares, contri- buindo ainda para a formação dos licenciandos e proporcionando um aprendizado recíproco entre esses acadêmicos em formação e os professores da rede de ensino. É importante salientar ainda, que ao se inserir na presente escola, o PIBID de Educação Física realizou um levantamento diagnostico investigando as carências da escola, dos alunos e da disciplina de Educação Física, para que assim pudéssemos ter um direcionamento tanto dos conteúdos a serem trabalhados como da metodologia a ser utilizada.

Contudo temos em vista que a escola necessita verificar sua própria capacidade de se adequar aos atuais contextos tecnológicos, os novos processos e as próprias mudanças na relação professor-aluno, sendo uma evolução e ao mesmo tempo um desafio trabalhar no ambiente multimídia, assim o objetivo da pesquisa foi diagnosticar o aspecto motivacional dos alunos em aulas de Educação Física quando o professor utiliza as TIC.

MOTIVAÇÃO PARA APRENDIZAGEM

No contexto escolar a motivação é um fator extremamente importante para que ocorra uma aprendizagem significativa por parte dos alunos, pois quando motivados estes se empenham mais nas atividades e na assimilação dos conteúdos curriculares das disciplinas.

0 aluno precisa gostar e querer ir para a escola de forma voluntária e não apenas fazê-lo por necessidade ou obrigação, e para isso, esse espaço precisa ser motivante e não apenas um local onde se transfere informação.

Quando falamos em motivação para a aprendizagem o professor é a peça principal para que isso ocorra da melhor forma, uma vez que este interfere diretamente no processo, seja através da metodologia que utiliza para ministrar seus conteúdos, seja com o estimulo/ recompensa dada ao aluno ao conseguir completar uma determinada tarefa.

Assim devemos pensar já durante o planejamento e durante o processo, como ensinar e qual a melhor estratégia é possível utilizar para tornar propícia a aprendizagem dos mais diversos conteúdos.

Segundo Bzuneck (5) "o professor precisa propor atividades que os alunos tenham condições de realizar e que despertem a curiosidade deles e os faça avançar. É necessário levá-los a enfrentar desafios, a fazer perguntas e procurar respostas.". Mas o que seria a motivação? Para Bzuneck (5) "a motivação é o que impulsiona uma pessoa para realizar uma determinada ação ou mudar uma determinada conduta." Assim, trazendo esse conceito para dentro da sala de aula, a motivação é a proposta, metodologia ou estratégia utilizada pelo professor, para instigar, impulsionar ou estimular a aprendizagem do alunado. 
PROGRAMA INSTITUCIONAL

COM BOLSA DE INICIAÇÃO À DOCÊNCIA

O Programa Institucional de Bolsa de Iniciação à Docência - PIBID é um programa do governo federal que funciona através do Ministério da Educação, por intermédio da Secretaria de Educação Superior - SESu, da Fundação Coordenação de Aperfeiçoamento de Pessoal de Nível Superior - CAPES e do Fundo Nacional de Desenvolvimento da Educação - FNDE, este programa foi criado com o intuito de promover a inserção dos discentes das universidades federais dos cursos de licenciatura na rede pública de ensino.

O subprojeto de Educação Física do PIBID busca apresentar para os bolsistas participantes do projeto como ocorre o funcionamento da escola da rede pública e qual a real situação da disciplina, onde segundo Barbosa et al. (7) esses bolsistas que ainda encontram-se na universidade, consegue por em prática os conhecimentos adquiridos na universidade, levando para o campo de atuação soluções dos possíveis problemas, novidades e motivação ainda enquanto acadêmicos, visto que na universidade ele tem maior possibilidade de refletir e intervir na realidade educacional.

De acordo com Barbosa et al. (6) o PIBID "vem possibilitando tanto uma formação de qualidade para os discentes (futuros profissionais), como também se apresenta como um recurso a mais de enriquecimento da prática pedagógica para os professores de Educação Física/supervisores" e assim a comunidade escolar ganhou em aquisições exitosas, uma vez que aliou as idéias inovadoras com a experiência dos professores/ tutores.

Barbosa et al. ${ }^{(6)}$ dizem que essa vivência no ambiente escolar por parte dos futuros professores, é vista como um incentivo em se tratando de docência e que tal experiência possibilita analisar, interagir e modificar a metodologia adotada nas aulas de Educação Física, para haver maior contribuição na qualidade da disciplina para a educação básica.

TECNOLOGIA DE INFORMAÇÃO

E COMUNICAÇÃO NAS AULAS DE EF

A sociedade já não é a mesma, encontra-se em constante processo de transformação. Silva e Penha ${ }^{(7)}$ dizem que "os processos educativos estão em evolução, os alunos já não são mais os mesmos, com formas de aprender e pensar diferentes, por que não mudar o jeito de ensinar?" Nascimento ${ }^{(8)}$ fala que vivemos hoje na sociedade da informação e que educar é um processo complexo e não o simples ato de treinar pessoas para o uso dessas TIC; trata-se de formar indivíduos autônomos capazes de interagir com as influências e os novos meios de forma criativa independente da atividade que venha a ser realizada.

Sebriam ${ }^{(4)}$ destaca que em qualquer disciplina os resultados positivos da utilização das TIC dependem do domínio que o professor apresenta sobre os recursos tecnológicos. E que a internet é uma ótima ferramenta educacional que inclusive possibilita desenvolver conteúdos destinados a pais e alunos possibilitando transcender os muros da escola po- dendo ser utilizada na EAD aumentando o tempo e espaço educacional. Entretanto, ressalta que os conflitos podem vir a surgir uma vez que a Educação Física em sua essência é uma disciplina prática e que através da utilização das TIC os professores podem vir com uma abordagem unicamente teórica. Salientando que mais uma vez cabe ao professor quebrar esse estigma.

É importante enfatizar também que as TIC têm na Educação Física o objetivo de fortalecê-la e dar novas alternativas e não com o intuito de substituir as atividades da cultura corporal do movimento e que também não devem ser utilizadas como um plano $B$, como salienta Capllonch apud Sebriam ${ }^{(4)}$ ao dizer que "em nenhum caso a tecnologia deve roubar o espaço da atividade motora ou ainda, converter-se em uma alternativa para os dias de chuva, ou quando não se dispõe de uma instalação". Estas devem ser utilizadas de acordo com o cronograma dentro do que foi planejado e sistematizado.

Na Educação Física teoria e prática se integram, assim com afirma Barbosa ${ }^{(9)}$ ao dizer que "a teoria é um processo interno, abstrato" é o pensamento em si "e a prática é o ato concreto que se pode ver, ouvir, sentir; é quando nosso interior entra em contato com o mundo exterior". Sendo assim, teoria e prática se completam e facilitam a aprendizagem do aluno.

Sebriam ${ }^{(4)}$ fala ainda que a utilização das TIC surge como um fator motivador para os alunos em sala de aula aumentando o desempenho no ensino de determinados conteúdos, porém há ainda uma certa escassez de iniciativas no Brasil. Sendo assim, é válido investigar as formas de utilização dessas tecnologias e qual o impacto elas trazem para os alunos envolvidos nestas aulas quanto sua à aceitação e motivação.

\section{METODOLOGIA}

Este estudo é definido como um estudo de caso descritivo, de natureza qualitativa, pois envolve a obtenção de dados descritivos sobre pessoas, lugares e processos interativos pelo contato direto do pesquisador com a situação estudada, procurando compreender os fenômenos segundo a perspectiva dos sujeitos, ou seja, dos participantes da situação em estudo ${ }^{(10)}$.

Para esta pesquisa o instrumento utilizado foi o questionário semi-aberto, que segundo Gil (11), é um instrumento com questões específicas, onde as respostas descrevem as características da população investigada, confirmando ou negando as hipóteses do estudo.

A população da pesquisa foi representada pelos estudantes do ensino médio, das turmas participantes do PIBID Educação Física, em uma escola da rede pública alagoana. A amostra foi constituída por 36 estudantes de ambos os gêneros sendo 20 alunos do 3ํano A e 16 alunos do $3^{\circ}$ ano $B$ do ensino médio.

Após autorização prévia por parte da direção da escola, foi agendado um dia de aula da disciplina de Educação Física para aplicação do questionário, assim a coleta de dados 
ocorreu na própria sala de aula, os alunos envolvidos foram informados da pesquisa e como a mesma iria ocorrer, todos os alunos receberam, leram e assinaram o TCLE, os alunos que se disseram menores de idade receberam um outro TCLE para que fosse assinado pelo responsável, assim se deu início a coleta de dados.

Para a análise dos dados foi utilizada a categorização pós fixada dos dados. Gil ${ }^{(11)}$ explica que as "respostas fornecidas pelos elementos pesquisados tendem a ser as mais variadas" e sendo assim cabe ao pesquisador organizá-las para que se faça a melhor análise possível e que esta organização requer a construção de algumas categorias. Com base nos resultados obtidos, realizamos a distinção em categorias, sendo estas denominadas por: Motivação, Processo de ensino-aprendizagem, Adequação das estratégias e Metodologia utilizada.

ENTENDENDO O DESENVOLVIMENTO DAS AULAS

QUE UTILIZAMOS TECNOLOGIAS DA INFORMAÇÃO E COMUNICAÇÃO

No começo do semestre realizou-se o planejamento junto à professora de Educação Física, assim foi feito um plano de curso com aulas que seriam ministradas através de vídeos, data-show e pesquisas na internet, de maneira teórica-prática, de acordo com conteúdos importantes para o dia-a-dia dos alunos e que teriam grande chance de serem incluídos no Exame Nacional do Ensino Médio - ENEM. No final de cada aula, como forma de avaliação, eram aplicados com os alunos: questionários, debates e redação que serviam como instrumento para possibilitar a melhora das aulas e ainda serviam como uma forma a mais para que os alunos conseguissem fixar os conteúdos.

Ao término da primeira unidade do planejamento, foi realizado um evento como estava previsto no projeto da escola, onde os alunos do $3^{0}$ ano puderam apresentar para a comunidade escolar o que foi aprendido em conjunto nas aulas do PIBID de Educação Física. Os temas que já tinham sido estudados foram: importância da atividade física; nutrição $x$ desnutrição; obesidade; como verificar Índice de Massa Corporal e Relação Cintura/Quadril; distúrbios alimentares: anorexia e bulimia; suplementos alimentares; anabolizantes; energéticos, como verificar a freqüência cardíaca e pressão arterial.

Após o evento de culminância foi realizada essa pesquisa para verificar se a proposta de utilização das TIC tiveram influência na motivação e aprendizagem dos alunos.

\section{RESULTADOS E DISCUSSÃo}

\section{DOS DADOS}

RESULTADOS QUANTO A MOTIVAÇÃO: UTILIZAÇÃO DAS TIC

$50 \%$ dos alunos se consideraram motivados quando são utilizadas TIC nas aulas de Educação Física. Os outros $50 \%$ dos alunos disseram que depende do conteúdo. Ninguém considerou que essa estratégia fosse desmotivante e inadequada.

Os sujeitos pesquisados que consideraram que as TIC são motivantes, disseram que:

É uma maneira diferente e motivante de aprendizado, ou seja, uma forma atrativa de fazer com que o aluno participe (Aluno 28)

Porque valoriza a aula interferindo muito na qualidade e se torna motivadora (Aluno 22).

Porém fica evidenciado na fala de outros sujeitos pesquisados que nem sempre devem/precisam ser utilizados:

As TIC muitas vezes motiva aos alunos porque faz a aula ser dinâmica e menos cansativa, mas tem assunto que não chama atenção(Aluno 4).

Tem conteúdo que não precisa utilizar (Aluno 21).

Confirmando a fala de Sebriam (4) "A utilização da tecnologia representa uma fonte de motivação para os alunos na aprendizagem de determinados conteúdosĐ, porém, nem todos, e no caso da Educação Física isto fica muito claro para os alunos. A dicotomia entre aprendizagens teóricas e práticas ainda é um debate central na Educação Física Escolar. Historicamente, vivendo num meio de práticas motoras a Educação Física escolar vive hoje o incômodo de ter que rever suas práticas pedagógicas, a partir do momento em que se transforma em componente curricular no currículo da Educação Básica. Enquanto a formação destes professores não se adequar totalmente as novas perspectivas para a educação nesta etapa de escolarização, os professores de Educação Física escolar continuarão ocupando o incômodo lugar de "educadores de corpos". [grifo nosso]

RESULTADOS QUANTO A MOTIVAÇÃO:

UTILIZAÇ̃̃O DAS REDES SOCIAIS

Em relação à utilização das redes sociais, $67 \%$ dos alunos foram a favor do uso da internet e das redes sociais na Educação Física.

Porém, 33\% dos alunos disseram que seria negativo, pois a maioria dos alunos só iria querer ficar no bate-papo ou iria thes tirar a atenção durante a explicação do professor.

A partir desta reflexão, decidimos não utilizar essa ferramenta em sala de aula, mais sim à distância, possibilitando aos alunos responder a indagações, acessar conteúdos das aulas, cronogramas, responder enquetes. 
Machado e Tijiboy ${ }^{(12)}$ listam uma série de contribuições ofertadas pelas redes sociais quando utilizadas de forma racional e educacional, de acordo com a criatividade e objetivos dos alunos e professores, podendo contribuir para a mobilização de saberes, servem como espaço de discussão sobre os diferentes temas, diagnosticar preferências, trabalhar a linguagem digital, trabalhar cooperativamente assuntos do interesse do aluno.

RESULTADOS QUANTO A MOTIVAÇÃO:

UTILIZAÇÃO DOS RECURSOS

Foram avaliados cada recurso individualmente, para verificar quais interferem positivamente na motivação dos alunos. Como mostra a tabela 1 a seguir.

TABELA1 - Motivação dos alunos de acordo com cada recurso

\begin{tabular}{cccccc}
\hline & $\begin{array}{c}\text { SEM } \\
\text { MOTIVAÇÃO }\end{array}$ & $\begin{array}{c}\text { POUCO } \\
\text { MOTIVADO }\end{array}$ & INDIFERENTE & MOTIVADO & $\begin{array}{c}\text { MUITO } \\
\text { MOTIVADO }\end{array}$ \\
\hline QUADRO CONVENCIONAL & $24 \%$ & $40 \%$ & $27 \%$ & $9 \%$ & $0 \%$ \\
\hline TV & $9 \%$ & $49 \%$ & $3 \%$ & $24 \%$ & $15 \%$ \\
\hline INTERNET & $6 \%$ & $9 \%$ & $9 \%$ & $36 \%$ & $40 \%$ \\
\hline VÍDEOS & $0 \%$ & $6 \%$ & $6 \%$ & $46 \%$ & $42 \%$ \\
\hline DATA-SHOW & $0 \%$ & $15 \%$ & $0 \%$ & $41 \%$ & $44 \%$ \\
\hline
\end{tabular}

Assim constatamos que o quadro convencional vem deixando de despertar o interesse dos alunos na escola onde se realizou o estudo, talvez em virtude das novas tecnologias que vêm surgindo e se apresentando sempre como facilitador, uma vez que outros recursos nos economizam tempo e oportunizam uma maior quantidade de informações. Algo que foi falado por um dos sujeitos pesquisados ao citar que "quando o professor utiliza o data-show não precisa copiar tanto $e$ já perde menos tempo, assim pode explicar melhor o assunto e passar mais conteúdo". (Aluno 4)

É importante constatar que nesta escola existe apenas um aparelho de data-show, comprovando a pouca utilização pelos seus professores.

RESULTADOS QUANTO AO PROCESSO DE ENSINO-APRENDIZAGEM

FACILITAÇÃO DA APRENDIZAGEM

Quanto ao uso das TIC 97\% dos alunos disseram que a utilização desses recursos facilita a aprendizagem dos conteúdos, e apenas um aluno disse que isso o deixa mais disperso e nenhum aluno afirmou que a utilização das TIC prejudicou a aprendizagem ou foi usada de maneira inadequada.
Essas tecnologias complementam a aula do professor, quando usada com sabedoria a aprendizagem é obtida com maior facilidade (Aluno 25)

A aula fica mais interessante porque deixa de ser monótona e fica mais motivante (Aluno 4).

Quando conseguimos visualizar o que vamos aprender memorizamos com mais facilidade (Aluno 9).

É bem mais atrativo, pois a participação, aprendizagem, socialização do grupo é praticamente total (Aluno 28)

Facilitam a aprendizagem, pois estamos vendo e obtendo mais informações através da imagem e também se torna uma aula mais dinâmica (Aluno 29).

Segundo Andrade (13) ao utilizar as TIC como ferramenta pedagógica a aprendizagem dos alunos torna-se facilitada porque estimulam os alunos, dinamizam os conteúdos e permitem a autonomia e criatividade destes.

RESULTADOS QUANTO A ADEQUAÇÃO

DAS ESTRATEGIAS/METODOLOGIA UTILIZADA

CONCENTRAÇÃO/ATENÇÃO DURANTE AS AULAS

97\% dos alunos alegaram que as aulas usando aparelhos eletrônicos chamam mais atenção e abrangem o conteúdo de forma mais simplificada e ilustrada. Apenas um aluno, o que coresponde a $3 \%$ disse que era indiferrnte e nenhum aluno afirmou ter sua atenção diminuída quando as aulas são ministradas através das mídias e tecnologias.

RESULTADOS QUANTO A ADEQUAÇÃO DAS ESTRATEGIAS

E METODOLOGIA UTILIZADA: SUPORTE POR PARTE DA ESCOLA

Ao indagar sobre a oferta de suporte por parte da escola para a utilização de TIC, 42\% disseram que a escola oferece sim suporte, uma vez que conta com equipamentos, como data-show e sala de vídeo. Apenas $8 \%$ disse que a escola não oferece de maneira alguma suporte para as TIC. Outros $50 \%$ dos alunos responderam que nem sempre a escola oferece suporte da melhor maneira, assim responderam porque a escola tem problemas recorrentes com o uso do laboratório de informática onde alguns alunos nunca chegaram a utilizá-lo. Outra dificuldade é a quantidade dos meios tecnológicos, onde alguns desses têm de ser reservado e quando um professor utiliza por exemplo um data-show outro professor não utiliza devido a quantidade de equipamentos. Não há uma rádio da escola vinculação da escola a plataformas que oferecem formação à distância, não há muita exploração de produção de tarefas em TIC pelos alunos da escola, enfim, muita coisa poderia ser melhor na escola $X$. 
Para contornar os problemas com o laboratório de informática realizamos tarefas extra-classe uma vez que quase em totalidade os alunos tinham acesso a internet fora da escola, e também num momento posterior conseguimos utilizar 3 computadores com acesso a internet que ficavam na biblioteca.

Como havia poucos equipamentos na escola, estes tinham de ser reservado antes junto a coordenação da escola, intensificado a importância do cronograma de planejamento.

Como normalmente o equipamento que os professores das demais disciplinas utilizavam era o data-show, esse problema foi solucionado utilizando um aparelho de TV, já que na escola existiam dois e quase sempre um estava disponível e estes fazem conexão com o notebook sendo possível a apresentação de slides e de vídeos.

RESULTADOS QUANTO A ADEQUAÇÃO DAS ESTRATEGIAS

E METODOLOGIA UTILIZADA: ACESSIBILIDADE

A grande maioria dos alunos afirmaram ter acesso a internet, onde $67 \%$ faz uso no próprio domicílio. Confirmando dados da PNAD (Pesquisa Nacional por Amostra de Domicílios) divulgada pelo IBGE ${ }^{(14)}$, onde o acesso a internet por parte da população brasileira com mais de 10 anos cresceu 143,8\% de 2005 para 2011, comparando ainda as faixas etárias, os jovens são os que mais acessam a internet. Onde o grupo entre 15 a 17 anos atingiram $(74,1 \%)$ e de 18 ou 19 anos atingiram (71,8\%).

$22 \%$ alegou utilizar a internet em lan house, $8 \%$ na casa de amigos e somente $3 \%$, o que coresponde a um aluno, alegou não ter acesso a internet, assim verificamos que podemos utilizá-la como ferramenta escolar para o desenvolvimento de atividades extra classe, uma vez que ninguém declarou fazer uso da internet na escola mostrando que a estrutura escolar pública ainda deixa a desejar em determinados aspectos.

\section{CONSIDERAÇõES FINAIS}

Diante dos relatos apresentados, podemos observar o quanto é benéfico para o processo ensino-aprendizagem a utilização de novas mídias, pois os alunos se sentem mais motivados, as aulas ficam mais interativas e participativas, entretanto nem sempre a escola é capaz de fornecer o suporte para que isto aconteça da melhor forma e muitas vezes o professor não tem formação para a sua utilização de forma pedagógica.

Em se tratando da disciplina Educação Física, atualmente ela vem ganhando força e importância no âmbito escolar, e as metodologias utilizadas são uma forma bastante interessante de apresentar as possibilidades da mesma, tanto para os alunos como para toda a comunidade escolar.
Considerando os objetivos do estudo, com as suas respectivas intervenções, notou-se um avanço por parte dos alunos, tanto na motivação verificada aqui, como na aprendizagem verificada nas atividades de sala de aula: questionários, avaliações, redações e aulas práticas. Essas práticas têm conseguido alcançar experiências significativas também para os monitores/bolsistas que no PIBID puderam aprender como agir e interagir dentro da escola.

Considerando as opiniões dos alunos participantes do estudo e do Programa PIBID de Educação Física da UFAL, é possível aportarmos as seguintes considerações que é maior a resistência dos professores de Educação Física em relação ao uso das TIC do que dos alunos. As respostas dos alunos declaram bem esta constatação. Os alunos não só aprovam o uso de novas tecnologias como também estão próximos destas tecnologias fora da escola. Portanto, precisamos agora alertar aos professores para realizarem um diagnóstico sobre mudanças metodológicas em suas aulas, repensarem quais as finalidades da Educação Física no contexto escolar como componente curricular e, finalmente, pensar como responderemos aos objetivos educacionais dos diferentes segmentos da educação básica previstos nas Diretrizes Curriculares do MEC e se a Educação Física que existe no PPP da escola está condizente com os objetivos educacionais da escola brasileira de hoje. Caso não esteja, aproveite os alunos num planejamento dialógico para encontrarem juntos uma sistematização da disciplina condizente com os ideais defendidos atualmente. 
AUTORES:

Diego H. Figueiredo

Diogo H. Figueiredo ${ }^{1}$

Marcelo de Oliveira Matta ${ }^{1}$

Faculdade de Educação Físic Juiz de Fora Minas Gerais, Brasil.

\section{Alterações da força explosiva após o período preparatório \\ em jovens atletas de Futebol}

\section{PALAVRAS CHAVE:}

Futebol. Força explosiva. Salto vertical.

2. Amadeu. S. (2008). Educar para a era digital. Revis-

ta Educação: os intelectuais que renovam a pedagogia.

São Paulo: Segmento, n. 108, p. 34

3. Marquès, P. (2000). Las TIC y sus aportaciones a

la sociedad. Disponivel em: <http://www.pangea.org/ peremarques/tic.htm>. Acesso em: 16 mai. 2013.

4. Sebriam, D. C. (2009). Utilização das tecnologias

da informação e comunicação no ensino de Educação Física. (Dissertação de Mestrado). Programa Erasmus Mundus - Mestrado em Engenharia de Mídias para a Educação - Portugal, Espanha e França

5. Bzuneck, J. A. (2000). As crenças de auto-eficácia dos professores. In: F.F. Sisto, G. de Oliveira, \& L. D. T. Fini (Orgs.). Leituras de psicologia para formação de professores. Petrópolis, Rio de Janeiro: Vozes, 2000 6. Barbosa, M. O. ; Melo, F. A. P. ; Lima, A. S. ; Santos, F. M. ; Montenegro, P. C. A. (2011). O PONTO DE VISTA DOS PROFESSORES DE EDUCAÇÃO FÍSICA SOBRE P PIBID EM SEUS CONTEXTOS ESCOLARES. In: XVII Congresso brasileiro de ciências do esporte, Porto Alegre. Ciência e compromisso social. Porto Alegre: UFRGS. v. XVII. p. 1-9

7. Silva, A. M.; Penha, M. G. (2012). 0 uso das tecnologias no ensino fundamental: novos desafios para o professor de educação física em uma escola pública de Goiânia Revista Eletrônica de Pedagogia. Jataí: V. 2 nำ13.

8. Nascimento, R. J. (2003). Uso das tecnologias de informação e comunicação na formação de professores de educação física e desporto: estudo experimental num módulo de basquetebol. (Tese de Doutorado). Lisboa, Portugal. Faculdade de Motricidade Humana, Universidade Técnica de Lisboa.

9. Barbosa, C. L. (1997). Educação Física Escolar da alienação à libertação. 1르 ed. Petrópolis: Vozes.

11. Gil, A. C. (2008). Métodos e técnicas de pesquisa cial. 60 ed. São Paulo: Atlas.

2. Machado, J.; Tijiboy, (2005). A. Redes sociais viruais: um espaço para efetivação da aprendizagen coperativa. 11. Novas tecnologias na educação, V. 3 № 1, Maio, 2005. Disponível em: <http://www.inf.ufes. br/ロcvnascimento/artigos/a37_redessociaisvirtuais. df> Acesso em: 24 mai. 2013

13. Andrade, A. (2011). 0 uso das Tecnologias na Educação: computador e internet. (monografia) Consórcio setentrional de EAD, Universidade de Brasília/Universidade estadual de Goiás no curso de licenciatura em biologia à distância.

14. IBGE. (2013). Acesso à internet no Brasil. Disponível em: <http://diariodonordeste.globo.com/noticia asp?codigo=359284>. Acesso em: 17 maio

\section{RESUMO}

0 processo de treinamento no futebol, assim como em vários esportes é extremamente complexo, pois trata-se de uma modalidade onde os atletas realizam funções específicas dentro da partida. Em sua grande maioria, os momentos decisivos do jogo ocorrem em lances de alta intensidade, com curtas distâncias e durações, sendo evidente a solicitação predominante dos membros inferiores. Nesta perspectiva, as manifestações de força estão ganhando importância como indicador de desempenho físico, e a técnica de salto vertical vem sendo utilizado como principal método para a medida de força. 0 principal objetivo deste trabalho foi refletir sobre questões relacionadas ao desenvolvimento da força explosiva em jovens futebolistas, durante um período de quatro semanas de treinamento preparatório. Participaram do estudo 17 atletas do sexo masculino, divididos pela categoria infantil $(n=9)$ e juvenil $(n=8)$, submetidos a avaliação de força explosiva de membro inferiores no inicio e ao final de uma pré-temporada. Os resultados sugerem que houve um aumento significativo no desempenho da força explosiva de membros inferiores entre o início e o final do período preparatório.

Correspondência: Diego Hilgemberg Figueiredo. Faculdade de Educacão Física e Desportos (Faefí) da Universidade Federal de Juiz de Fora, Minas Gerais, Brasil (diegohilgemberg@ @otmail.com). 